\title{
La preocupante anarquía en la práctica de la cirugía general en México
}

\author{
The worrying anarchy in the practice of general surgery in Mexico
}

Jorge Cervantes*

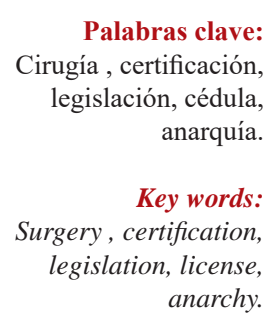

* Dr. Jorge Cervantes

Castro

Centro Médico ABC

Observatorio

jcervantes

@abchospital.com

Recibido: 07/09/2016

Aceptado: 26/09/2016
$\mathrm{S}_{\mathrm{s}}^{\mathrm{e}}$ e desconoce el número de cirujanos generales que ejercen su profesión en México y, también, si éstos son en realidad verdaderos cirujanos generales que cuentan con la certificación del Consejo Mexicano de Cirugía General como tal o si se trata del típico "médico cirujano" graduado por las más de 120 escuelas de medicina del país que expiden el título incorrecto de "médico cirujano" o alguna variante que incluye la palabra "cirujano" a la mayoría de sus egresados.

Sin duda alguna es necesario efectuar una investigación cuidadosa sobre quiénes, cómo y dónde están actualmente efectuando operaciones quirúrgicas en México.

Se conoce el número de escuelas de medicina. ${ }^{1}$ Se sabe que sólo un tercio de ellas cuenta con la certificación mediante el Reconocimiento de Validez Oficial de Estudios (RVOE). Se tiene una idea aproximada, que entre 12 y 15 mil médicos generales se gradúan cada año, y sabemos que la gran mayoría de dichas escuelas expide el título de "médico cirujano" o alguna variante que incluya la palabra "cirujano" y que, con esos documentos, el médico acude a la Dirección General de Profesiones para que ésta les expida la cédula de profesiones, una patente para ejercer lo que el título dice. La cédula es personal, intransferible, permanente, no tiene caducidad y es válida en todo el territorio nacional.

Amparados en dichos títulos y cédulas, muchos médicos incursionan en la práctica de la cirugía sin que exista alguna autoridad que regule o verifique su actuación.

Respecto al número de cirujanos generales activos en el país o el número de "médicos cirujanos" que sin entrenamiento formal efec- túan cotidianamente intervenciones quirúrgicas en hospitales y clínicas privadas, se solicitó a la Asociación Mexicana de Cirugía General información sobre los cirujanos generales que tiene registrados; nos dieron la cifra de 2,491. Pero para dar una idea de la irregularidad que tenemos, las cifras del reciente Congreso $\mathrm{Na}$ cional de la Asociación celebrado en la ciudad de Monterrey, N.L. en octubre del 2015 revelan más de 4,000 "cirujanos" registrados. ${ }^{2}$

Otro dato más interesante, cuando en noviembre del 2014 se solicitó al Consejo Mexicano de Cirugía General el número de cirujanos generales que cuentan con la certificación vigente, se observó que sólo 2,182 tienen este documento. ${ }^{3}$

Indudablemente persisten muchas irregularidades en el quién, cómo, dónde y qué tipo de médicos están practicando cirugías en nuestro país, y mientras no se regule lo anterior, seguiremos observando complicaciones y tragedias.

La Dirección General de Información en Salud de la Secretaría de Salud (DGIS), tiene registrados en el país en el año 2014 a un total de 387,187 médicos, y cerca de 4 millones de operaciones. Seguramente la gran mayoría de esos médicos tiene el título de "médico cirujano" que es el que expide más del $80 \%$ de las escuelas y facultades de medicina del país, y posiblemente muchos de ellos son los que efectúan los casi 4 millones de operaciones anualmente en el sector salud. ${ }^{4}$

A raíz de los cambios en el reglamento del artículo 81 y subsecuentes de la Ley General de Salud del primero de septiembre del 2011, respecto a que se requiere el certificado de la especialidad a todo médico que desee involucrarse en actividades quirúrgicas, es preocu- 
pante ver que de 387,187 médicos del sector oficial de salud sólo estén registrados 8,424 como de "cirugía general y de especialidades" y, presumiblemente, esos 8,424 sean los que efectuaron las 3,637,048 operaciones al año, lo que da un total de 432 intervenciones quirúrgicas realizadas cada año, en promedio, por cada uno de los médicos registrados.

De estos 8,424 médicos no se especifica cuántos son verdaderos "cirujanos generales" que estén debidamente certificados o que sólo sean los típicos "médicos cirujanos".

En consecuencia, estamos en México ante la situación de que miles de médicos amparados por un título de "médico cirujano" o alguna variante que incluya la palabra "cirujano" efectúan en el sector salud los cerca de 4 millones de intervenciones quirúrgicas al año amparados en los antes mencionados títulos.

Se sabe el número de intervenciones quirúrgicas del sector oficial por año y por institución pero no se sabe el tipo de operaciones por especialidad, ni el número de complicaciones y muertes secundarias a dichos procedimientos, que puede ser considerable si se observa el gran número de quejas que recibe cada año la Comisión Nacional de Arbitraje Médico (CONAMED). ${ }^{5}$

No se conoce el número de intervenciones quirúrgicas efectuadas cada año en el país por médicos del sector privado, ni se sabe cuántos de éstos son en realidad verdaderos especialistas en cirugía, ni qué número de "médicos cirujanos" efectúan todo tipo de intervenciones quirúrgicas en los cientos de hospitales y clínicas privadas en todo el territorio nacional.

Aquí vale la pena preguntar quién está vigilando que se cumpla lo estipulado en la última modificación a la Ley General de Salud del 1 de septiembre del 2011 referente a que sólo los cirujanos que cuenten con la certificación vigente deberían estar practicando intervenciones quirúrgicas.

Respecto al marco legal de la práctica de la cirugía, nos referimos a la Ley de Profesiones en México, en la que el Artículo $5^{\circ}$ establece que "a ninguna persona podrá impedirse que se dedique a la profesión, industria, comercio o trabajo que le acomode, siendo lícito".

El Artículo $5^{\circ}$ también establece que: "para ejercer la profesión se requiere una cédula que expide la Dirección General de Profesiones; dicha cédula es personal, intransferible, no tiene caducidad y es válida en todo el territorio nacional". Así, amparados por el título y la cédula correspondiente ya sea de "médico cirujano" o algunas de las variantes que expiden las 120 escuelas de medicina, los médicos en México están autorizados legalmente para practicar la profesión indicada en ambos documentos, sin que haya autoridad que certifique o verifique que el portador de dicho documento está efectivamente capacitado para hacerlo. En otras palabras, no existe impedimento para que el médico mexicano pueda ejercer su profesión en todo el territorio nacional, ya que de acuerdo con el Artículo 121 en su Fracción V especifica que: "los títulos profesionales expedidos por un Estado, con sujeción a sus leyes, serán respetados en los otros". . $^{6-10}$

Actualmente, para la práctica de las profesiones se sigue aplicando la Ley de la Dirección General de Profesiones expedida en México en 1945, con algunas modificaciones para intentar regular la realidad profesional totalmente distinta. Como se podrá advertir sin mayor complicación, esta ley se ha visto rebasada en múltiples aspectos por la evolucionada realidad social. ${ }^{11}$

A diferencia de otras carreras y de otras especialidades, la medicina, y en particular la cirugía, están sujetas a una serie de regulaciones, como son los exámenes de admisión para ingresar a un programa de especialización, el requisito de lograr la certificación y recertificación de los especialistas. ${ }^{10}$

Para entender mejor estos requerimientos, ausentes en otras disciplinas como arquitectura, contaduría y derecho, por enumerar sólo algunas, basta con explicar que en esta profesión se pone en juego lo más valioso del individuo, su vida y se necesitan criterios estrictos de selección sobre quién y cómo será responsable de ella. ${ }^{12}$

\section{REFERENCIAS}

1. Cervantes J. Urge un Abraham Flexner en México. Cir Cir. 2014; 82: 473-475.

2. Dato consultado en la Asociación Mexicana de Cirugía General, Julio 2016.

3. Dato consultado en el Consejo Mexicano de Cirugía General, Julio 2016. 
4. Catálogos abiertos de bases de datos Dirección General de Información en Salud (DGIS, 2014).

5. Dato consultado en el Informe Anual de CONAMED, 2015.

6. Athie-Gutiérrez C. Aspectos legales de la certificación profesional en la cirugía general y el cirujano. En: Vega-Malagón JA. La cirugía general y el cirujano. México: Universidad Autónoma de Querétaro; 2011. p. 391-397.

7. Rodríguez-Abraham A. El marco jurídico del ejercicio profesional de la cirugía general. En: Vega-Malagón J. La cirugía general y el cirujano. México: Universidad Autónoma de Querétaro; 2011. p. 327-329.
8. Arenas-Márquez H. Calidad en salud y su relación con el proceso de certificación y recertificación. Cir Gen. 2002; 24: 72-77.

9. Arenas-Márquez $\mathrm{H}$. Estado actual: ser y quehacer de la cirugía general en la perspectiva de la Asociación Mexicana de Cirugía General. Cir Gen. 1996; 18: 51-52.

10. Díaz-Piña A. Marco legal de las profesiones en México. Rev Alegatos. 2013; 85: 1009-1025.

11. Moreno-Garavilla J. El ejercicio de las profesiones en el Estado Federal Mexicano. México: Edit. M. Porrúa; 2011.

12. Cervantes J. Las implicaciones legales del título de Médico Cirujano [Tesis Doctoral]. Facultad de Derecho, UNAM; 2016. 